\title{
Irritable Bowel Syndrome Is Associated With Gastroesophageal Reflux Symptom but Not Erosive Esophagitis
}

\author{
Su Youn Nam, ${ }^{1,2 *}$ Kum Hei Ryu ${ }^{1,2}$ and Bum Joon Park ${ }^{1,2}$ \\ ${ }^{1}$ Department of Internal Medicine, ${ }^{2}$ Center for Cancer Prevention \& Detection, National Cancer Center; Goyang, Gyeonggi-do, Korea
}

\begin{abstract}
Background/Aims
Although several studies have suggested overlaps between gastroesophageal reflux symptom and irritable bowel syndrome (IBS), the studies for the association between erosive esophagitis and IBS are rare. The aim of this study was to evaluate the association among IBS, non-erosive reflux disease (NERD), and erosive esophagitis.
\end{abstract}

\section{Methods}

A total of 2,769 participants completed questionnaires and underwent esophagogastroduodenoscopy and colonoscopy. IBS was diagnosed by Rome III; NERD was defined as heartburn or acid regurgitation occurring at least once per week without erosive esophagitis. Erosive esophagitis was defined by Los Angeles classification. Psychological distress was evaluated with modified 4 dimensions from revised Hopkins symptom checklist 90.

\section{Results}

Psychological distress was associated with both IBS and NERD, but not with erosive esophagitis. IBS was associated with somatization (adjusted $O R, 2.88 ; 95 \% \mathrm{Cl}, 1.55-5.36 ; P<0.001$ ), anxiety (adjusted $\mathrm{OR}, 2.82 ; 95 \% \mathrm{Cl}, 1.36-5.88 ; P=0.005$ ), and hostility (adjusted $O R, 2.06 ; 95 \% \mathrm{Cl}, 1.10-3.87 ; P=0.024$ ) and NERD was associated with somatization (adjusted OR, 5.65; $95 \% \mathrm{Cl}, 2.92-10.98 ; P<0.001$ ) and anxiety (adjusted $\mathrm{OR}, 3.29 ; 95 \% \mathrm{Cl}, 1.47-7.34 ; P=0.004$ ). Erosive esophagitis was associated with somatization (adjusted OR, 2.69; $95 \% \mathrm{Cl}, 1.26-7.91 ; P<0.001$ ). Hiatal hernia and male sex were related with erosive esophagitis but not with IBS or NERD. H. pylori had an inverse relationship with erosive esophagitis, but had no association with IBS. Whereas IBS was positively associated with NERD (adjusted OR, 2.72; 95\% Cl, 1.84-4.03; $P<0.001$ ), it had no association with erosive esophagitis.

\section{Conclusions}

IBS shared many risk factors with NERD but not with erosive esophagitis. It partially explains why IBS was associated with

Received: April 17, 2013 Revised: September 13, 2013 Accepted: September 15, 2013

(c) This is an Open Access article distributed under the terms of the Creative Commons Attribution Non-Commercial License (http://creativecommons. org/licenses/by-nc/3.0) which permits unrestricted non-commercial use, distribution, and reproduction in any medium, provided the original work is properly cited.

*Correspondence: Su Youn Nam, MD, PhD

Department of Internal Medicine, Center for Cancer Prevention and Detection, National Cancer Center, 323 Ilsan-ro, Ilsandong-gu, Goyang-si, Gyeonggi-do 411-769, Korea

Tel: +82-31-920-1608, Fax: +82-31-920-0451, E-mail: mascha@ncc.re.kr

Financial support: This study was supported by a grant (No. NCC 0810200-1) from the National Cancer Center, Korea. The funding source had no role in the design or conduct of the study; management, analysis or interpretation of the data; or the preparation, review or approval of manuscript. The funding source did have a role in the collection of the questionnaires and was financially responsible for the abdominal multi-detector computed tomography.

Conflicts of interest: None.

Author contributions: Nam SY had a main responsibility for the conception and design of the study, data collection, data analysis and writing the manuscript. Ryu KH and Park BJ contributed to the acquisition of data and critical revision of the manuscript. All authors reviewed and approved the final version to be published. 
NERD, but not with erosive esophagitis.

(J Neurogastroenterol Motil 2013;19:521-531)

\section{Key Words}

Erosive esophagitis; Gastroesophageal reflux symptom; Irritable bowel syndrome; Non-erosive reflux disease

\section{Introduction}

Irritable bowel syndrome (IBS) is a chronic, recurrent intestinal problem, characterized by bloating, abdominal pain and changes in bowel habit. Although the prevalence and incidence reported depend on the criteria used, most studies agree that it is a common disorder frequently seen by general practitioners and specialists. ${ }^{1,2}$ The prevalence of IBS has been reported as approximately $10 \%$ in the Western population ${ }^{2,3}$ and as $2.6 \%$ to $9.6 \%$ in the Korean population. ${ }^{4-6}$

Many reports have suggested overlaps between IBS and gastroesophageal reflux symptoms (GERS ${ }^{4,7-10}$; these overlaps occur predominantly in patients with anxiety. ${ }^{4}$ However, previous population-based studies did not exclude organic bowel disease from IBS by colonoscopy. ${ }^{4,7-10}$ A recent study suggested that non-erosive reflux disease (NERD) is more frequently overlapped with epigastric pain syndrome and IBS than erosive esophagitis. ${ }^{11}$ However, this study did not consider Helicobacter pylori as a confounding factor, which is highly prevalent in Korea and has been strongly associated with gastroesophageal reflux disease (GERD). ${ }^{12}$ Although there are the evidences of the positive association between IBS and NERD, the relationship between IBS and erosive esophagitis is controversial. In the present study, we evaluated the potential relationship of IBS with NERD and erosive esophagitis after adjusting many potential confounding factors including $H$. pylori and psychological stress while excluding organic bowel diseases by using colonoscopy and laboratory tests.

\section{Materials and Methods}

\section{Study Population and Questionnaire Assessment}

The Obesity and Gastrointestinal Disorder Study, which was launched at the Center for Cancer Prevention and Detection, Korean National Cancer Center in February 2008, uses a large self-motivated health screening cohort. ${ }^{13}$ In the present study, we included subjects who underwent a comprehensive screening program including colonoscopy and esophagogastroduodenoscopy and responded to questionnaires from April 2008 to November 2008, a part of Obesity and Gastrointestinal Disorder Study. We excluded subjects who had colorectal cancer, previous colorectal surgery, hysterectomy, and other abdominal or pelvic surgery, inflammatory disease of colon, abnormal thyroid function, previous $H$. pylori eradication, and recent users of proton pump inhibitors (PPIs), $\mathrm{H}_{2}$ blockers, NSAIDs and steroid (Figure).

The enrolled subjects were racially homogeneous Koreans. Personal data (age, sex, alcohol consumption, smoking status, family history, personal medical history, medication history, gastrointestinal symptoms, psychological distress, job and socioeconomic status) were collected before both colonoscopy and esophagogastroduodenoscopy. Smoking status was classified as current smoker (daily or occasionally) or non-current smoker; alcohol consumption status was also classified as current drinker or non-current drinker. Two well trained research nurses interviewed the subjects and completed the questionnaires.

\section{Assessment of Psychological Distress}

To measure the psychological distress, we used modified scales of the revised Hopkins symptom checklist 90 (SCL-90-R), which is a widely used measure of psychological distress. This instrument contains 90 questions addressing nine dimensions of symptoms: somatization, obsessive-compulsiveness, interpersonal sensitivity, depression, anxiety, hostility, phobic anxiety, paranoid ideation, and psychosis. ${ }^{14}$ We measured somatization (12 items), anxiety (10 items), depression (13 items) and hostility (6 items) among 9 dimensions. The questions are multiple-choice and graded on a $0-4$ scale, with higher scores indicating more distress. We used sum of the score of each item in each dimension. The definition of risk group and disease group was defined as the scores over $1 \mathrm{SD}$ and $2 \mathrm{SD}$ comparing with sex-specific mean in general population. A psychiatrist (Kim HK) performed validation of the psychological distress. The disease group was very rare and we used only the risk group in the present study. 


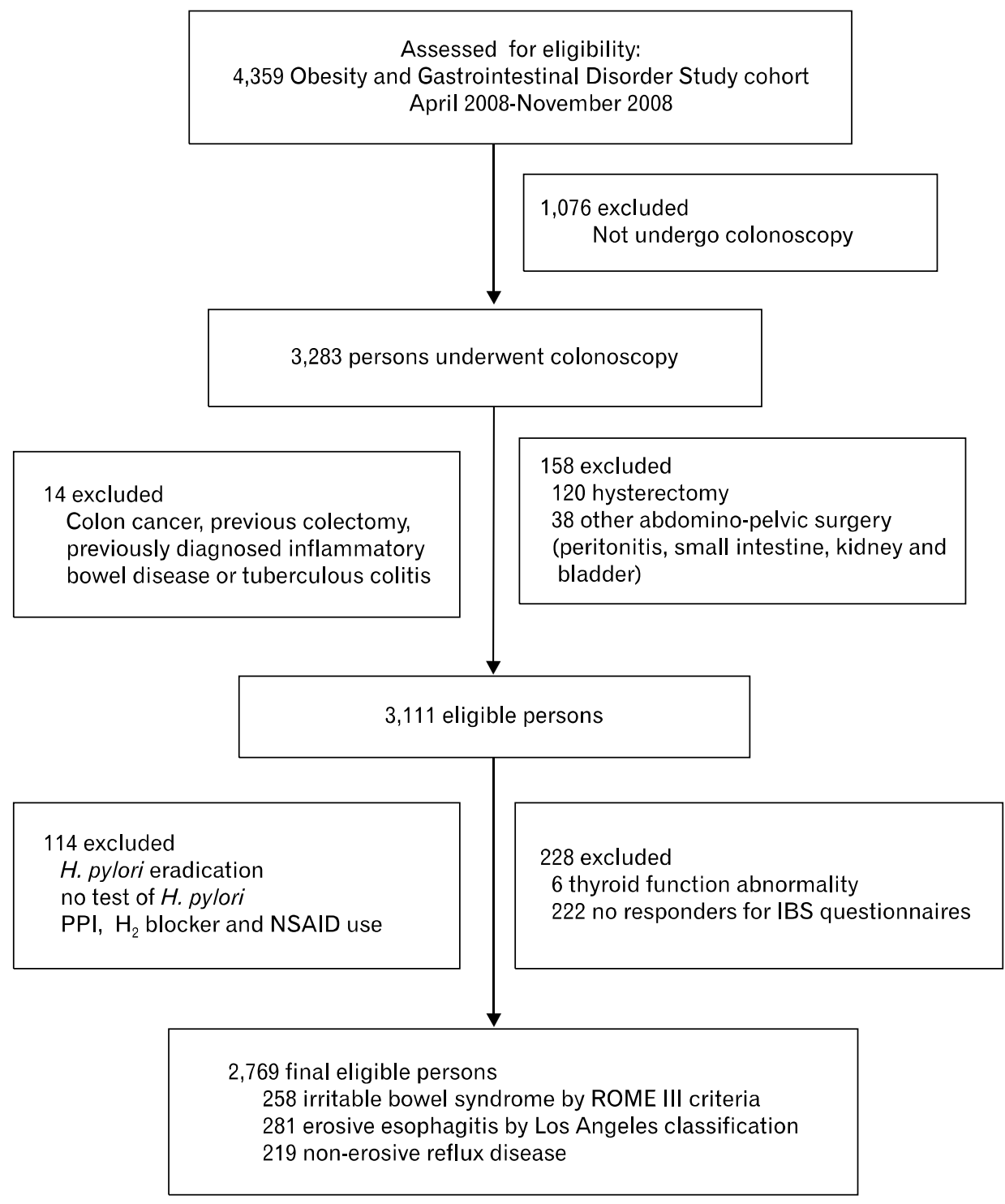

Figure. Flow of study participants. $H$. pylori, Helicobacter pylori; PPI, proton pump inhibitor; $\mathrm{H}_{2}$, histamine receptor 2; NSAID, non-steroid anti-inflammatory drug; IBS, irritable bowel syndrome.
The definition of each risk group was the score of $\geq 18$ in men and $\geq 23$ in women for somatization, the score $\geq 17$ in men and $\geq 19$ in women for anxiety, the score $\geq 25$ in men and $\geq 28$ in women for depression, and the score $\geq 11$ in men and $\geq 10$ in women for hostility.

\section{Assessment of Gastrointestinal Symptoms}

We evaluated patients for typical GERS as well as extraesophageal symptoms (globus sensation, hoarseness, epigastric soreness and chronic cough). GERS was diagnosed as heartburn and/or acid regurgitation occurring at least once per week. Heartburn was defined as "a burning sensation or discomfort in the substernal area, soreness in the substernal area, or a burning sensation induced by swallowing," and acid regurgitation as "a bitter or sour-tasting fluid coming into your throat or mouth." ${ }^{15}$ Globus sensation was defined as "a foreign body sensation in the throat or a sensation of food (like steak) in the substernal area." The frequency of symptoms was reported as: none in the past year, less than once a month, about once a month, about once a week, several times a week, and daily. Severity of symptoms was reported as: mild ("can be ignored if I do not think about it"), moderate ("cannot be ignored but does not affect my lifestyle"), severe ("affect my life style or disturbing work or sleeping").

IBS was diagnosed according to the Rome III criteria, ${ }^{16}$ which have been validated. IBS was defined as recurrent abdominal pain or discomfort (at least 3 days per month in the last 3 months) with onset at least 6 months before diagnosis and associated with 2 or more of the following: (1) improvement in pain 
with defecation, (2) onset associated with a change in the frequency of stools and (3) onset associated with a change in the form of stools.

\section{Measurement of Obesity}

Weight and height measurement was automated (X-SCAN PLUS II; Jawon Medical Co, Kyungsan, Korea), and body mass index (BMI) was calculated as weight $/$ height $^{2}\left(\mathrm{~kg} / \mathrm{m}^{2}\right)$. Waist circumference was measured by trained nurses at the midpoint between the lower borders of the rib cage and highest point of the iliac crest.

We measured abdominal adipose tissue volume by a method previously described and validated. ${ }^{13}$ In summary, participants underwent CT in a supine position using a 64-multidetector CT (Brilliance 64; Philips, Best, Netherlands). Contiguous 5-mm slices $(120 \mathrm{kVp} ; 150 \mathrm{~mA}$; gantry rotation time, $750 \mathrm{~ms}$ ) were acquired, and adipose tissue volume was measured using 20 slices. Abdominal fat compartments were manually traced in each image, segmentation of the 20 slices was automatically reconstructed, and volume $\left(\mathrm{cm}^{3}\right)$ was calculated using software (Extended Brilliance Workspace version 3.5; Philips).

\section{Endoscopy}

Esophagogastroduodenoscopy was performed using a flexible endoscope (Q260; Olympus Optical Co., Ltd., Tokyo) on subjects who had fasted overnight. Pharyngeal anesthesia with xylocaine spray and conscious sedation $(0.06 \mathrm{mg} / \mathrm{kg}$ midazolam $)$ were provided routinely. The severity of reflux esophagitis seen on endoscopy was graded from A to D according to the Los Angeles (LA) classification system. ${ }^{17}$ To evaluate inter-observer reproducibility, four experienced gastroenterologists performed all endoscopic procedures. To estimate inter-observer variation, we reviewed picture archiving and communications system (PACS) images of a random subset of 40 cases, each lasting approximately 30 seconds, together in a single conference room and recorded gastroesophageal findings. Presence of hiatus hernia or other gastroduodenal lesion was recorded. During each endoscopic examination, the biopsy specimen was obtained at the greater curvature of the body for $H$. pylori evaluation with a rapid urease test. Hiatus hernia was recorded if the gastroesophageal junction was seen to extend at least $2 \mathrm{~cm}$ above the diaphragmatic hiatal impression during quiet respiration. Measurement of hiatus hernia was performed at the start of endoscopic examination before inflation of stomach or at the end of endoscopic examination after deflation of stomach. ${ }^{18}$ NERD was defined by positive GERS without definite esophagitis.
The day before the colonoscopy, the particpants ingested 45 $\mathrm{mL}$ aqueous Fleet Phospho-soda (Fleet Company, Inc, Lynchburg, VA, USA) in $240 \mathrm{~mL}$ water, and $10 \mathrm{mg}$ bisacodyl tablets followed by 1,500 $\mathrm{mL}$ water at $7 \mathrm{pm}$. At $10 \mathrm{pm}$, they ingested another $45 \mathrm{~mL}$ aqueous Fleet Phospho-soda in $240 \mathrm{~mL}$ water followed by 1,500 $\mathrm{mL}$ water. We performed the colonoscopy with a colonoscope (Q260AL; Olympus Optical Co, Ltd, Tokyo, Japan), recording the location and size of all polypoid and sessile lesions. All polyps or cancers removed endoscopically or surgically were fixed in formaldehyde and sent to pathologic laboratory for routine histologic examination.13 The histological evaluation was made according to World Health Organization (WHO) criteria.

All endoscopic examinations were performed by experienced gastroenterologists blind to the results of the questionnaire. The study was approved by the National Cancer Center institutional review board. Informed consent for sedated endoscopy and use of personal data for research purposes was obtained from all participants before endoscopy.

\section{Statistical Methods}

We assessed inter-observer agreement for esophageal lesions using kappa statistics. The prevalence of IBS, NERD and erosive esophagitis was expressed as percentage. ANOVA test was performed to comapre 3 groups. Pearson chi-square test or independent $t$ test was used to determine the difference in risk factors between each pair of groups (presence of IBS vs. absence of IBS, presence of NERD vs. absence of NERD, and presence of erosive esophagitis vs. absence of erosive esophagitis). The effects of NERD, erosive esophagitis, and confounding factors on IBS were estimated by logistic regression analysis and expressed as odds ratios (ORs) and 95\% confidence intervals (CIs). Significant risk factors revealed by univariate analysis were confirmed by multivariate logistic regression. We determined the associations among IBS, NERD, and erosive esophagitis.

We used STATA software (version 10; College Station, TX, USA) for our analyses. All statistical tests were two-sided, and $P$ $<0.05$ was considered statistically significant.

\section{Results}

\section{Characteristics of Eligible Subjects and Total Subjects}

Of the 4,359 subjects in the Obesity and Gastrointestinal Disorder Study cohort from April 2008 to November 2008, 
2,769 subjects met the study inclusion criteria (Figure). The prevalence of IBS, NERD and erosive esophagitis (LA classification, A to D) was $9.3 \%, 7.9 \%$, and $10.1 \%$, respectively. Age, sex, waist circumference, life style factors, chronic disease, sedative use, and antidepressant use did not differ between the total subjects in the cohort and the eligible subjects who participated in the present study (data not shown). The kappa values for erosive esophagitis for the 4 readers were 0.86 for grade A, 0.93 for grade $\mathrm{B}$ and 0.91 for grade $\mathrm{C}$.

\section{Risk Factors for Irritable Bowel Syndrome and Gastroesophageal Reflux Disease}

Both IBS and NERD were associated with younger age, current smoker, absence of $H$. pylori infection, antidepressant use, and higher scores of somatization, anxiety, depression and hostility, but they were not associated with hypertension, diabetes mellitus, and sedative use (Tables 1 and 2). Current drinker status was associated with IBS but not with NERD. Current smoker is a common risk factor for IBS, NERD and erosive esophagitis. IBS was related with lower waist circumference, however, erosive esophagitis was related with higher waist circumference. Psychological distress classified by normal and risk group showed that risk groups for somatization, anxiety, depression and hostility had a positive association with IBS and NERD, but erosive esophagitis had no association with psychological distress except somatization.

\section{Multivariate Analysis of Risk Factors for Irritable Bowel Syndrome and Gastroesophageal Reflux Disease}

Whereas IBS and NERD demonstrated a strong positive association with somatization and anxiety, erosive esophagitis had association with only somatization (Table 3 ). IBS was also related with hostility. Whereas NERD was associated with female sex, erosive esophagitis was associated with male sex. Whereas IBS decreased with increasing age, NERD and erosive esopahgitis had no association with age. Higher waist circumference was related with NERD and erosive esophagitis, but not with IBS. Absence of $H$. pylori and current smoker was associated with erosive esophagitis, but not with NERD nor IBS. Erosive esophagitis was positively associated with presence of hiatus hernia, but IBS and NERD were not related.

\section{Association Between Irritable Bowel Syndrome and Gastroesophageal Reflux Disease}

IBS demonstrated a strong positive association with NERD, but no association with erosive esophagitis (Table 4). The presence of NERD increased the risk of IBS up to 2.7-fold (adjusted OR, 2.72; 95\% CI, 1.84-4.03; $P<0.001$ ) (Table 4). IBS was also positively associated with atypical GERS: hoarseness (adjusted OR, 1.83; 95\% CI, 1.34-2.51; $P<0.001$ ), globus sensation

Table 1. Rsik Factors for Irritable Bowel Syndrome

\begin{tabular}{|c|c|c|c|}
\hline & Absence of IBS $(\mathrm{n}=2,511)$ & Presence of IBS $(n=258)$ & $P$-value \\
\hline Male sex (n [\%]) & $1,513(60.3)$ & $169(65.5)$ & 0.100 \\
\hline Age (mean $[\mathrm{SD}], \mathrm{yr}$ ) & $50.2(9.9)$ & $45.3(8.6)$ & $<0.001$ \\
\hline Waist circumference (mean [SD]) & $85.3(8.1)$ & $84.1(8.3)$ & 0.018 \\
\hline Current smoker (n [\%]) & $708(28.2)$ & $105(40.7)$ & $<0.001$ \\
\hline Current drinker (n [\%]) & $1,619(64.5)$ & $195(75.6)$ & $<0.001$ \\
\hline Hypertension (n [\%]) & $467(18.6)$ & $37(14.3)$ & 0.091 \\
\hline Diabetes (n [\%]) & $137(5.5)$ & $16(6.2)$ & 0.618 \\
\hline Use of sedative (n [\%]) & $17(0.7)$ & $4(1.6)$ & 0.124 \\
\hline Use of antidepressant ( $\mathrm{n}[\%]$ ) & $28(1.1)$ & $7(2.7)$ & 0.029 \\
\hline Hiatus hernia (n [\%]) & $59(2.4)$ & $7(2.7)$ & 0.708 \\
\hline H. pylori (n [\%]) & $1,224(48.8)$ & $106(41.1)$ & 0.019 \\
\hline \multicolumn{4}{|l|}{ Psychological distress (n [\%]) } \\
\hline Risk group for somatization & $44(1.8)$ & $25(9.7)$ & $<0.001$ \\
\hline Risk group for anxiety & $49(2.0)$ & $30(11.6)$ & $<0.001$ \\
\hline Risk group for depression & $44(1.8)$ & $24(9.3)$ & $<0.001$ \\
\hline Risk group for hostility & $55(2.2)$ & $27(10.5)$ & $<0.001$ \\
\hline
\end{tabular}

IBS, irritable bowel syndrome as diagnosed by Rome III criteria; H. pylori, Helicobacter pylori. 
Table 2. Risk Factors for Gastroesophageal Reflux Disease

\begin{tabular}{lcccc}
\hline \multicolumn{1}{c}{ Risk factors } & $\begin{array}{c}\text { Absence of erosive esophagitis } \\
\text { and NERD (n=2,269) }\end{array}$ & $\begin{array}{c}\text { NERD } \\
(\mathrm{n}=219)\end{array}$ & $\begin{array}{c}\text { Erosive esophagitis }_{(\mathrm{n}=281)} \\
P \text {-value }\end{array}$ \\
\hline Age (mean [SD], yr) & $49.8(10.0)$ & $48.9(9.6)$ & $49.9(9.7)$ & 0.698 \\
Male sex (n [\%]) & $1,324(58.4)$ & $111(50.7)$ & $247(87.9)$ & $<0.001$ \\
Waist circumference (mean [SD]) & $84.7(8.2)$ & $85.6(7.3)$ & $88.5(7.3)$ & 0.056 \\
Current smoker (n [\%]) & $617(27.2)$ & $67(30.6)$ & $128(45.7)$ & $<0.001$ \\
Current drinker (n [\%]) & $1,454(64.1)$ & $138(63.0)$ & $222(79.0)$ & $<0.001$ \\
Hypertension (n [\%]) & $403(17.8)$ & $40(18.3)$ & $61(21.7)$ & 0.270 \\
Diabetes (n [\%]) & $120(5.3)$ & $4(3.7)$ & $4(1.4)$ & 0.020 \\
Use of sedative (n [\%]) & $13(0.6)$ & $6(2.7)$ & $3(1.1)$ & 0.050 \\
Use of antidepressant (n [\%]) & $26(1.2)$ & $4(1.8)$ & $25(8.9)$ & 0.125 \\
Hiatus hernia (n [\%]) & $37(1.6)$ & $96(43.8)$ & $76(27.1)$ & $<0.001$ \\
H. pylori (n [\%]) & $1,158(51.0)$ & $20(9.1)$ & $14(5.0)$ & $7(2.5)$ \\
Psychological distress (n [\%]) & $35(1.5)$ & $18(8.2)$ & $8(2.9)$ & $<0.001$ \\
Risk group for somatization & $54(2.4)$ & $9(4.1)$ & $12(4.3)$ & $<0.001$ \\
Risk group for anxiety & $51(2.25)$ & $11(5.0)$ & 0.213 \\
Risk group for depression & $59(2.6)$ & & 0.050 \\
Risk group for hostility & & & \\
\hline
\end{tabular}

NERD, non-erosive reflux disease; H. pylori, Helicobacter pylori.

${ }^{a} A N O V A$ test was performed to compare 3 groups.

Table 3. Risk Factors for Irritable Bowel Syndrome and Gastroesophageal Reflux Disease in Multivariate Analysis

\begin{tabular}{|c|c|c|c|c|c|c|}
\hline \multirow{2}{*}{ Risk factors } & \multicolumn{2}{|l|}{ IBS } & \multicolumn{2}{|l|}{ NERD } & \multicolumn{2}{|c|}{ Erosive esophagitis $^{a}$} \\
\hline & $\mathrm{OR}^{\mathrm{b}}(95 \% \mathrm{CI})$ & $P$-value & $\mathrm{OR}^{\mathrm{b}}(95 \% \mathrm{CI})$ & $P$-value & $\mathrm{OR}^{\mathrm{b}}(95 \% \mathrm{CI})$ & $P$-value \\
\hline Male sex & $1.29(0.89-1.88)$ & 0.182 & $0.55(0.38-0.80)$ & 0.002 & $3.38(2.21-5.21)$ & $<0.001$ \\
\hline Age (yr) & $0.95(0.94-0.97)$ & $<0.001$ & $0.99(0.98-1.00)$ & 0.289 & $1.00(0.99-1.02)$ & 0.899 \\
\hline Waist circumference & $0.98(0.97-1.00)$ & 0.109 & $1.03(1.01-1.05)$ & 0.005 & $1.04(1.02-1.06)$ & $<0.001$ \\
\hline Current smoker & $1.30(0.95-1.77)$ & 0.098 & $1.37(0.96-1.96)$ & 0.085 & $1.49(1.11-1.98)$ & 0.007 \\
\hline Current drinker & $1.23(0.88-1.73)$ & 0.221 & $1.04(0.74-1.45)$ & 0.831 & $1.14(0.81-1.61)$ & 0.454 \\
\hline Diabetes & $1.73(0.97-1.06)$ & 0.061 & $0.76(0.36-1.60)$ & 0.469 & $1.37(0.84-2.22)$ & 0.207 \\
\hline Use of antidepressant & $2.04(0.77-5.37)$ & 0.150 & $1.78(0.68-4.69)$ & 0.242 & $0.48(0.12-1.84)$ & 0.284 \\
\hline Presence of hiatus hernia & $0.86(0.36-1.04)$ & 0.740 & $1.03(0.36-2.99)$ & 0.950 & $4.42(2.47-7.90)$ & $<0.001$ \\
\hline Presence of $H$. pylori & $0.80(0.61-1.05)$ & 0.108 & $0.77(0.58-1.02)$ & 0.070 & $0.32(0.24-0.42)$ & $<0.001$ \\
\hline \multicolumn{7}{|l|}{ Psychological distress $^{c}$} \\
\hline Risk group for somatization & $2.88(1.55-5.36)$ & 0.001 & $5.65(2.92-10.98)$ & $<0.001$ & $2.69(1.26-7.91)$ & 0.010 \\
\hline Risk group for anxiety & $2.82(1.36-5.88)$ & 0.005 & $3.29(1.47-7.34)$ & 0.004 & $0.74(0.22-2.51)$ & 0.629 \\
\hline Risk group for depression & $1.25(0.56-2.81)$ & 0.586 & $0.32(0.11-0.94)$ & 0.038 & $0.89(0.28-2.77)$ & 0.838 \\
\hline Risk group for hostility & $2.06(1.10-3.87)$ & 0.024 & $0.96(0.42-2.24)$ & 0.941 & $1.48(0.65-3.39)$ & 0.353 \\
\hline
\end{tabular}

${ }^{a}$ Erosive esophagitis refers to reflux esophagitis, Los Angeles classification (A-D); ${ }^{b}$ Adjusted for age, sex, waist circumference, smoking status, drinking status, hiatus hernia, Helicobacter pylori, diabetes, use of antidepressant and psychological distress. Age and waist circumference were measured as continuous variables; ${ }^{\circ}$ Psychologica! distress was measured by partial questionnaires from revised Hopkins symptom checklist 90.

IBS, irritable bowel syndrome as diagnosed by Rome III critera; NERD, non-erosive reflux disease; OR, odds ratio; CI, confidence interval; H. pylori, Helicobacter pylori Risk group for somatization, $\geq 18$ in men and $\geq 23$ in women; risk group for anxiety, $\geq 17$ in men and $\geq 19$ in women; risk group for depression, $\geq 25$ in men and $\geq 28$ in women; risk group for hostility, $\geq 11$ in men and $\geq 10$ in women.

(adjusted OR, 3.41; 95\% CI, 2.56-4.53; $P<0.001$ ), chronic cough (adjusted OR, 2.19; 95\% CI, 1.59-3.01; $P<0.001$ ), and epigastric soreness (adjusted OR, 3.41; 95\% CI, 2.57-4.54; $P<$ $0.001)$. 
Table 4. Association Between Irritable Bowel Syndrome and Gastroesophageal Reflux Disease

\begin{tabular}{|c|c|c|c|c|}
\hline & \multicolumn{2}{|c|}{ NERD } & \multicolumn{2}{|c|}{ Erosive esophagitis $^{a}$} \\
\hline & $\mathrm{OR}^{\mathrm{b}}(95 \% \mathrm{CI})$ & $P$-value & $\mathrm{OR}^{\mathrm{b}}(95 \% \mathrm{CI})$ & $P$-value \\
\hline IBS by Rome III & $2.72(1.84-4.03)$ & $<0.001$ & $1.25(0.80-1.93)$ & 0.327 \\
\hline
\end{tabular}

${ }^{a}$ Erosive esophagitis refers to Los Angeles classification (A-D); ${ }^{\mathrm{b}}$ Adjusted for age, sex, waist circumference, smoking status, drinking status, hiatus hernia, Helicobacter pylori, diabetes, use of antidepressant and psychological distress. Age and waist circumference were measured as continuous variables.

NERD, non-erosive reflux disease; IBS, irritable bowel syndrome as diagnosed by Rome III criteria; OR, odds ratio; CI, confidence interval.

Table 5. Overlap of Irritable Bowel Syndrome and Non-erosive Reflux Disease in Multivariate Analysis

\begin{tabular}{|c|c|c|c|c|c|c|}
\hline & \multicolumn{2}{|c|}{ IBS alone $(\mathrm{n}=211)$} & \multicolumn{2}{|c|}{ NERD alone $(\mathrm{n}=172)$} & \multicolumn{2}{|c|}{ Overlap of IBS and NERD $(n=47)$} \\
\hline & $\mathrm{OR}^{\mathrm{a}}(95 \% \mathrm{CI})$ & $P$-value & $\mathrm{OR}^{\mathrm{a}}(95 \% \mathrm{CI})$ & $P$-value & $\mathrm{OR}^{\mathrm{a}}(95 \% \mathrm{CI})$ & $P$-value \\
\hline Male sex & $1.33(0.88-2.00)$ & 0.170 & $0.45(0.30-0.68)$ & $<0.001$ & $0.85(0.38-1.87)$ & 0.679 \\
\hline Age (yr) & $0.95(0.94-0.97)$ & $<0.001$ & $0.99(0.98-1.01)$ & 0.551 & $0.96(0.93-0.99)$ & 0.013 \\
\hline Waist circumference, $\mathrm{cm}$ & $0.98(0.97-1.00)$ & 0.221 & $1.03(1.01-1.05)$ & 0.004 & $0.98(0.95-1.03)$ & 0.481 \\
\hline Current smoker & $1.45(1.04-2.02)$ & 0.030 & $1.52(1.02-2.25)$ & 0.038 & $0.82(0.38-1.78)$ & 0.619 \\
\hline Current drinker & $1.36(0.93-1.99)$ & 0.11 & $1.11(0.76-1.62)$ & 0.580 & $0.88(0.44-1.74)$ & 0.712 \\
\hline Diabetes & $1.79(0.98-3.28)$ & 0.06 & $0.66(0.28-1.55)$ & 0.345 & $1.24(0.28-5.54)$ & 0.777 \\
\hline Presence of $H$. pylori & $0.82(0.61-1.10)$ & 0.18 & $0.96(0.65-1.22)$ & 0.480 & $0.67(0.36-1.25)$ & 0.207 \\
\hline Antidepressant use & $2.08(0.70-6.18)$ & 0.19 & $0.95(0.34-2.17)$ & 0.939 & $3.20(0.61-16.8)$ & 0.169 \\
\hline \multicolumn{7}{|l|}{ Psychological distress ${ }^{\mathrm{b}}$} \\
\hline Risk group for somatization & $1.86(0.86-4.04)$ & 0.116 & $3.11(1.33-7.23)$ & 0.009 & $13.96(5.49-35.47)$ & $<0.001$ \\
\hline Risk group for anxiety & $2.95(1.25-6.94)$ & 0.013 & $3.68(1.41-9.59)$ & 0.008 & $5.16(1.51-17.63)$ & 0.009 \\
\hline Risk group for depression & $1.14(0.46-2.87)$ & 0.774 & $0.16(0.03-0.86)$ & 0.033 & $0.67(0.16-2.77)$ & 0.578 \\
\hline Risk group for hostility & $2.32(1.17-4.59)$ & 0.016 & $0.98(0.33-2.87)$ & 0.969 & $1.30(0.39-4.30)$ & 0.672 \\
\hline
\end{tabular}

${ }^{a}$ Reference is neither IBS nor NERD, ${ }^{b}$ Psychological distress was measured by partial questionnaires from revised Hopkins symptom checklist 90.

IBS, irritable bowel syndrome; NERD, non-erosive reflux disease; $H$. pylori, Helicobacter pylori; OR, odds ratio; CI, confidence interval.

Age and waist circumference were measured as continuous variables.

\section{Overlap of Irritable Bowel Syndrome and Non-erosive Reflux Disease}

IBS alone had an inverse relationship with age and had a positive association with current smoker status, anxiety, and hostility. NERD alone was positively associated with female sex, increasing waist circumference, current smoker status, somatization, and anxiety and was negatively associated with depression. Overlapping IBS and NERD decreased with increasing age and had a strong association with somatization and anxiety (Table 5).

\section{Discussion}

We found that IBS shared psychological distress, such as somatization and anxiety, with NERD, demonstrating a strong positive association with NERD; however, IBS was not associated with erosive esophagitis after adjusting many confounding factors including $H$. pylori status.
Recent meta-analysis showed that odd ratio of GERS in individuals with IBS was four-fold that of individuals without IBS. ${ }^{19}$ Although previous population-based studies suggested a positive association between IBS and GERS, ${ }^{4,7,10}$ these studies did not exclude organic bowel disease by colonoscopy or laboratory tests and the study for the association between IBS and erosive esophagitis is rare. One previous study suggested that NERD is more frequently overlapped with IBS, compared to erosive esophagitis. ${ }^{11}$ However, that study did not consider $H$. pylori, which is strongly associated with GERD. ${ }^{12,15}$ In the present study, IBS had a strong positive association with NERD, but no association with erosive esophagitis after adjusting many confounding factors including psychological stress and $H$. pylori infection. The prevalence of IBS was increased up to 2.7-fold in NERD. The prevalence of IBS was increased up to 1.8-3.4-fold in the presence of atypical GERS. The strong association between IBS and NERD may be due to the sharing of psychological distress such as somatization and anxiety. Patients with 
IBS have greater psychological distress ${ }^{20}$ than people who do not have IBS, and are more often depressed, anxious, or hypochondriacal. ${ }^{1,21-24}$ Although results of previous studies suggested that psychological distress was increased in secondary and tertiary care, them of recent, large, population-based studies suggested that patients with IBS in the community also have increased psychological distress compared with individuals who do not have IBS. $^{21,25,26}$ In a previous study, acute stress modified gut-specific efferent autonomic innervations, and normalization was delayed in persons with IBS. ${ }^{27}$ In fact, experimentally induced anxiety modified gastric sensorimotor function, ${ }^{28}$ and persons with IBS revealed enhanced modulation of visceral perception with auditory stress. ${ }^{29}$ In the present study, IBS shared somatization and anxiety with NERD and also shared somatization with erosive esophagitis. IBS alone was positively associated with younger age, current smoker, anxiety and hostility. NERD alone was positively associated with female sex, higher waist circumference, current smoker, somatization, and anxiety but negatively associated with depression. Overlap of IBS and NERD was positively associated with younger age, somatization and anxiety. In the previous several studies, the overlap of IBS and GERS was relatively common, and this overlap occured predominantly in individuals with anxiety, ${ }^{4}$ insomnia, and nervousness. ${ }^{7}$ IBS and NERD shared the somatization and anxiety, which is more strongly predisposed to overlap of IBS and NERD compared to IBS alone or NERD alone. Therefore, the presence of IBS might explain PPI treatment failure in patients with overlap of IBS and NERD.

Although there are some evidences of the positive association between IBS and NERD, the relationship between IBS and erosive esophagitis is controversial. A recent survey by Neumann et $\mathrm{al}^{30}$ suggested that IBS is common in entire spectrum of GERD (NERD, erosive esophagitis, and Barrett's esophagus). In randomized clinical trial of 626 patients with reflux esophagitis, pantoprazole was efficacious in the treatment of patients suffering from overlap symptoms of GERD, functional dyspepsia and/or IBS, providing a sustained post-treatment response in functional dyspepsia and IBS symptom categories. ${ }^{31}$ In recent Chinese study of 1,030 individuals, who underwent endoscopy, IBS was not associated with reflux esophagitis. ${ }^{32}$ In the present study, IBS had no association with erosive esophagitis after adjusting risk factors even if they shared somatization. Apparently, no relationship between IBS and erosive esophagitis, despite of sharing somatization, might have originated from that erosive esophagitis is predisposed to the definitely different risk factors such as sex, age, $H$. pylori and hiatal hernia than from those of IBS.

Our findings for the relationship of IBS with NERD and erosive esophagitis on the basis of predisposing factors may have important clinical implications in the management of GERD, according to the presence or absence of IBS. Actually, recent studies suggested that GERD patients who had a functional bowel disorder showed a lower response rate to PPI as compared to those without a functional bowel disease. ${ }^{33}$ In contrast to this results, PPI was able to improve IBS-like symptoms, particularly in NERD in a German study. ${ }^{34}$ A randomized clinical trial suggested that pantoprazole was efficacious in the treatment of patients with an overlap of GERD and IBS provided a sustained post-treatment response in IBS symptom categories. ${ }^{31}$ It is needed to evaluate a personalized therapy in GERD patients according to concomitant functional bowel diseases and underlying pathophysiology.

The association between IBS and H. pylori is rarely evaluated. Even if the contribution of $H$. pylori on the hypersensitivity in IBS is suspected experimentally, ${ }^{35}$ a few clinical data showed controversial results. Recent 177 case-control study suggested that diarrhea dominant IBS had a positive relationship with $H$. pylori infection. ${ }^{36}$ Especially, virulence markers (cagA and vacA1) were related with diarrhea dominant IBS. ${ }^{36}$ In a recent Chinese study of 1,030 individuals, who underwent endoscopy, IBS had no association with $H$. pylori infection. ${ }^{32}$ In our study, IBS had a negative relationship with $H$. pylori infection in univariate analysis but it had no relationship in multivariate analysis.

The prevalence of IBS also increased according to decreasing age in the present study. The inverse relationship between IBS and age has been suggested in previous studies in Korea, but did not always show a statistical significance for this association. ${ }^{5,6}$ Similarly, previous studies from Western populations have also suggested the positive association between IBS and young age. ${ }^{2,25,37}$ In the present study, IBS had no association with sex. Although previous population-based studies from Korea demonstrated a similar prevalence of IBS in both sexes, ${ }^{4-6}$ a lot of studies from Western populations have also reported female predominance in IBS. ${ }^{2,37,38}$

Whereas somatization and anxiety were prone to NERD, depression was related with the low risk of NERD in the present study. The relationship between reflux symptom, depression, and anxiety was suggested in a previous study. ${ }^{39}$ Increasing waist circumference was also positively associated with NERD. This result is consistent with the studies from Western populations re- 
porting a strong positive association between GERS and $\mathrm{BMI}^{40,41}$ or abdominal obesity. ${ }^{42}$ Mechanisms that induce reflux include transient lower esophageal sphincter relaxation, ${ }^{43}$ higher gastroesophageal pressure gradients, hiatus hernia ${ }^{44}$ and excess endogenous estrogen. ${ }^{41}$ However, in patients with NERD, visceral hypersensitivity and psychological stress are also important contributing factors. ${ }^{39,45}$ Therefore, the evaluation for NERD should also consider psychosocial stress as well as acid regurgitation. Absence of $H$. pylori was a borderline risk factor for NERD and a strong risk factor for erosive esophagitis in present study. In contrast to erosive esophagitis, which had a constantly negative association with $H$. pylori, ${ }^{46,47}$ the association between GERS and $H$. pylori serology was inconsistent. ${ }^{48,49}$ Erosive esophagitis was positively associated with male sex, higher waist circumference, current smoker, hiatus hernia, and the absence of H. pylori. These findings are consistent with previous Korean studies. ${ }^{13,50}$

Population-based studies showed that the prevalence of IBS as assessed by Rome II or III was $2.2 \%$ to $9.6 \%$ in Korea. ${ }^{4-6}$ Prevalence of IBS (9.3\%) found in the present study was similar with results of previous studies. ${ }^{4,5}$ In the present study, the prevalence of NERD and erosive esophagitis (7.9\% and $10.1 \%$, respectively) was higher than that reported in previous Korean studies. ${ }^{15,50}$ A nation-wide prospective study in 2005 reported the prevalence of NERD and erosive esophagitis as $5 \%$ and $8 \%$, respectively. The different results for NERD and erosive esophagitis prevalence may be due to different study populations. The present study had a lower proportion of participants with an income of less than 1,000 USD per month (1\% vs. $8 \%$ ), lower rate of $\mathrm{H}$. pylori infection ( $48 \%$ vs. $64 \%)$ and higher BMI ( $\geq 25$, $34 \%$ vs. $31 \%$ ) compared with a previous nationwide study. ${ }^{15}$ Our previous observational study reported a low prevalence of erosive esophagitis $(6 \%)^{50}$; however, data was collected by many gastroenterologists over a long period of time, and the study did not evaluate inter-observer agreement for endoscopic diagnosis.

This study has several strengths. First, this is the study to evaluate the relationships of IBS with NERD and erosive esophagitis after adjusting many potential confounding factors including $H$. pylori, which has a strong negative association with GERD, and psychological stress. Second, our data were of high quality. Questionnaires for personal information, psychological distress, and symptoms of IBS and GERD were collected by two well-trained research nurses and endoscopic examinations were performed by gastrointestinal specialists. Erosive esophagitis was objectively evaluated by esophagogastroduodenoscopy and cate- gorized by the LA classification. The kappa value of reflux esophagitis for the 4 doctors was very high. Anthropometric parameters were measured directly. We excluded organic bowel diseases using colonoscopy and laboratory tests in screening subjects. Finally, the large size of the study, allowed us to evaluate subpopulations and their association after adjusting for a lot of confounding factors.

This study also had several limitations. First, the study population was a self-motivated screening cohort; therefore, selection bias may exist. The prevalence of IBS in the present study was similar to that found in population-based studies that used telephone interview surveys. ${ }^{4,5}$ Population-based studies using colonoscopy and esophagogastroduodenoscopy may not be realistic; therefore, the present study using a screening cohort without serious underlying disease may present as an alternative. Second, only $64 \%$ of the participants were eligible for the present study. However, eligible participants and excluded subjects did not differ significantly by age, sex, waist circumference, smoking status, chronic disease, NERD or erosive esophagitis. Third, we checked only 4 dimensions among 9 dimensions in SCL-90-R. Although the definition of risk group in this study has not been well known, we performed internal validation for the psychological distress in National Cancer Center by a psychiatrist. Fourth, even if this cross-sectional study suggested the association between IBS and NERD and their shared risk factors, it did not show the effect of managing the shared risk factors. Therefore its clinical implication was limited. Finally, we did not assess diet, which could affect reflux symptoms.

In conclusion, IBS shared psychological distress, such as somatization and anxiety, with NERD and was positively associated with NERD; however, IBS was not associated with erosive esophagitis even if they shared somatization. This finding may have important implications in the management of GERD, according to the presence or absence of IBS. In the future, it is needed to evaluate a personalized therapy in GERD patients according to concomitant functional bowel diseases and underlying pathophysiology.

\section{Acknowledgements}

The authors appreciate Park KW for performing esophagogastroduodenoscopies, Kim HK (a psychiatrist) for validation of psychological distress, and research nurses Yoon SH and Park YJ for interviewing participants. 


\section{References}

1. Russo MW, Gaynes BN, Drossman DA. A national survey of practice patterns of gastroenterologists with comparison to the past two decades. J Clin Gastroenterol 1999;29:339-343.

2. Andrews EB, Eaton SC, Hollis KA, et al. Prevalence and demographics of irritable bowel syndrome: results from a large web-based survey. Aliment Pharmacol Ther 2005;22:935-942.

3. Spiller R, Aziz Q, Creed F, et al. Guidelines on the irritable bowel syndrome: mechanisms and practical management. Gut 2007;56: 1770-1798.

4. Lee SY, Lee KJ, Kim SJ, Cho SW. Prevalence and risk factors for overlaps between gastroesophageal reflux disease, dyspepsia, and irritable bowel syndrome: a population-based study. Digestion 2009;79: 196-201.

5. Han SH, Lee OY, Bae SC, et al. Prevalence of irritable bowel syndrome in Korea: population-based survey using the Rome II criteria. J Gastroenterol Hepatol 2006;21:1687-1692.

6. Jeong JJ, Choi MG, Cho YS, et al. Chronic gastrointestinal symptoms and quality of life in the Korean population. World J Gastroenterol 2008;14:6388-6394.

7. Jung HK, Halder S, McNally M, et al. Overlap of gastro-oesophageal reflux disease and irritable bowel syndrome: prevalence and risk factors in the general population. Aliment Pharmacol Ther 2007;26:453-461.

8. Talley NJ. Overlapping abdominal symptoms: why do GERD and IBS often coexist? Drugs Today (Barc) 2006;42(suppl B):3-8.

9. Lembo A, Zaman M, Jones M, Talley NJ. Influence of genetics on irritable bowel syndrome, gastro-oesophageal reflux and dyspepsia: a twin study. Aliment Pharmacol Ther 2007;25:1343-1350.

10. Cheung TK, Lam KF, Hu WH, et al. Positive association between gastro-oesophageal reflux disease and irritable bowel syndrome in a Chinese population. Aliment Pharmacol Ther 2007;25:1099-1104.

11. Noh YW, Jung HK, Kim SE, Jung SA. Overlap of erosive and non-erosive feflux diseases with functional gastrointestinal disorders according to Rome III criteria. J Neurogastroenterol Motil 2010; 16:148-156.

12. Nam SY, Choi IJ, Ryu KH, Kim BC, Kim CG, Nam BH. Effect of Helicobacter pylori infection and its eradication on reflux esophagitis and reflux symptoms. Am J Gastroenterol 2010;105:2153-2162.

13. Nam SY, Kim BC, Han KS, et al. Abdominal visceral adipose tissue predicts risk of colorectal adenoma in both sexes. Clin Gastroenterol Hepatol 2010;8:443-450, e1-e2.

14. Derogatis LR, Rickels K, Rock AF. The SCL-90 and the MMPI: a step in the validation of a new self-report scale. Br J Psychiatry 1976;128:280-289.

15. Kim N, Lee SW, Cho SI, et al. The prevalence of and risk factors for erosive oesophagitis and non-erosive reflux disease: a nationwide multicentre prospective study in Korea. Aliment Pharmacol Ther 2008;27:173-185.

16. Longstreth GF, Thompson WG, Chey WD, Houghton LA, Mearin F, Spiller RC. Functional bowel disorders. Gastroenterology 2006;130:1480-1491.

17. Armstrong D, Bennett JR, Blum AL, et al. The endoscopic assess- ment of esophagitis: a progress report on observer agreement. Gastroenterology 1996;111:85-92.

18. Zagari RM, Fuccio L, Wallander MA, et al. Gastro-oesophageal reflux symptoms, oesophagitis and Barrett's oesophagus in the general population: the Loiano-Monghidoro study. Gut 2008;57:13541359.

19. Lovell RM, Ford AC. Prevalence of gastro-esophageal reflux-type symptoms in individuals with irritable bowel syndrome in the community: a meta-analysis. Am J Gastroenterol 2012;107:1793-1801.

20. Whitehead WE, Palsson O, Jones KR. Systematic review of the comorbidity of irritable bowel syndrome with other disorders: what are the causes and implications? Gastroenterology 2002;122:1140-1156.

21. Choung RS, Locke GR 3rd, Zinsmeister AR, Schlech CD, Talley NJ. Psychosocial distress and somatic symptoms in community subjects with irritable bowel syndrome: a psychological component is the rule. Am J Gastroenterol 2009;104:1772-1779.

22. Bennett EJ, Piesse C, Palmer K, Badcock CA, Tennant CC, Kellow JE. Functional gastrointestinal disorders: psychological, social, and somatic features. Gut 1998;42:414-420.

23. Drossman DA, Camilleri M, Mayer EA, Whitehead WE. AGA technical review on irritable bowel syndrome. Gastroenterology 2002;123:2108-2131.

24. Gros DF, Antony MM, McCabe RE, Swinson RP. Frequency and severity of the symptoms of irritable bowel syndrome across the anxiety disorders and depression. J Anxiety Disord 2009;23:290-296.

25. Locke GR 3rd, Yawn BP, Wollan PC, Melton LJ 3rd, Lydick E, Talley NJ. Incidence of a clinical diagnosis of the irritable bowel syndrome in a United States population. Aliment Pharmacol Ther 2004;19:1025-1031.

26. Pan G, Lu S, Ke M, Han S, Guo H, Fang X. Epidemiologic study of the irritable bowel syndrome in Beijing: stratified randomized study by cluster sampling. Chin Med J (Engl) 2000;113:35-39.

27. Murray CD, Flynn J, Ratcliffe L, Jacyna MR, Kamm MA, Emmanuel AV. Effect of acute physical and psychological stress on gut autonomic innervation in irritable bowel syndrome. Gastroenterology 2004;127:1695-1703.

28. Geeraerts B, Vandenberghe J, Van Oudenhove L, et al. Influence of experimentally induced anxiety on gastric sensorimotor function in humans. Gastroenterology 2005;129:1437-1444.

29. Dickhaus B, Mayer EA, Firooz N, et al. Irritable bowel syndrome patients show enhanced modulation of visceral perception by auditory stress. Am J Gastroenterol 2003;98:135-143.

30. Neumann H, Monkemuller K, Kandulski A, Malfertheiner P. Dyspepsia and IBS symptoms in patients with NERD, ERD and Barrett's esophagus. Dig Dis 2008;26:243-247.

31. Mönnikes H, Schwan T, van Rensburg C, et al. Randomised clinical trial: sustained response to PPI treatment of symptoms resembling functional dyspepsia and irritable bowel syndrome in patients suffering from an overlap with erosive gastro-oesophageal reflux disease. Aliment Pharmacol Ther 2012;35:1279-1289.

32. Zhao Y, Zou D, Wang R, et al. Dyspepsia and irritable bowel syndrome in China: a population-based endoscopy study of prevalence and impact. Aliment Pharmacol Ther 2010;32:562-572.

33. Heading RC, Mönnikes H, Tholen A, Schmitt H. Prediction of response to PPI therapy and factors influencing treatment outcome in patients with GORD: a prospective pragmatic trial using pantopra- 
zole. Heading RC, BMC Gastroenterol 2011;11:52.

34. Mönnikes H, Heading RC, Schmitt H, Doerfler H. Influence of irritable bowel syndrome on treatment outcome in gastroesophageal reflux disease. World J Gastroenterol 2011;17:3235-3241.

35. Gerards C, Leodolter A, Glasbrenner B, Malfertheiner P. H. pylori infection and visceral hypersensitivity in patients with irritable bowel syndrome. Dig Dis 2001;19:170-173.

36. Yakoob J, Abbas Z, Naz S, Islam M, Jafri W. Virulence markers of Helicobacter pylori in patients with diarrhoea-dominant irritable bowel syndrome. Br J Biomed Sci 2012;69:6-10.

37. Gomez Alvarez DF, Morales Vargas JG, Rojas Medina LM, Mújica Oviedo SC, Camacho López PA, Rueda Jaimes GE. [Prevalence of irritable bowel syndrome and associated factors according to the Rome III diagnostic criteria in a general population in Colombia.] Gastroenterol Hepatol 2009;32:395-400. [Spanish].

38. Katsinelos P, Lazaraki G, Kountouras J, et al. Prevalence, bowel habit subtypes and medical care-seeking behaviour of patients with irritable bowel syndrome in Northern Greece. Eur J Gastroenterol Hepatol 2009;21:183-189.

39. Jansson C, Nordenstedt $\mathrm{H}$, Wallander MA, et al. Severe gastro-oesophageal reflux symptoms in relation to anxiety, depression and coping in a population-based study. Aliment Pharmacol Ther 2007;26:683-691.

40. Jacobson BC, Somers SC, Fuchs CS, Kelly CP, Camargo CA Jr. Body-mass index and symptoms of gastroesophageal reflux in women. N Engl J Med 2006;354:2340-2348.

41. Nilsson M, Johnsen R, Ye W, Hveem K, Lagergren J. Obesity and estrogen as risk factors for gastroesophageal reflux symptoms. JAMA 2003;290:66-72.

42. Corley DA, Kubo A, Zhao W. Abdominal obesity, ethnicity and gastro-oesophageal reflux symptoms. Gut 2007;56:756-762.

43. Wu JC, Mui LM, Cheung CM, Chan Y, Sung JJ. Obesity is associated with increased transient lower esophageal sphincter relaxation. Gastroenterology 2007;132:883-889.

44. Wilson LJ, Ma W, Hirschowitz BI. Association of obesity with hiatal hernia and esophagitis. Am J Gastroenterol 1999;94:2840-2844.

45. Knowles $\mathrm{CH}$, Aziz Q. Visceral hypersensitivity in non-erosive reflux disease. Gut 2008;57:674-683.

46. Koike T, Ohara S, Sekine H, et al. Helicobacter pylori infection prevents erosive reflux oesophagitis by decreasing gastric acid secretion. Gut 2001;49:330-334.

47. Rajendra S, Ackroyd R, Robertson IK, Ho JJ, Karim N, Kutty KM. Helicobacter pylori, ethnicity, and the gastroesophageal reflux disease spectrum: a study from the East. Helicobacter 2007;12:177-183.

48. Nordenstedt H, Nilsson M, Johnsen R, Lagergren J, Hveem K. Helicobacter pylori infection and gastroesophageal reflux in a population-based study (The HUNT Study). Helicobacter 2007;12:1622.

49. Corley DA, Kubo A, Levin TR, et al. Helicobacter pylori and gastroesophageal reflux disease: a case-control study. Helicobacter 2008; 13:352-360

50. Nam SY, Choi IJ, Nam BH, Park KW, Kim CG. Obesity and weight gain as risk factors for erosive oesophagitis in men. Aliment Pharmacol Ther 2009;29:1042-1052. 